\title{
SOME ESTIMATES FOR HAUSDORFF OPERATORS
}

\section{Guilian Gao, Xiaomei Wu, Amuad Hussain and Guoping Zhao}

Abstract. In this paper, we give some sufficient conditions for the boundedness of three types of Hausdorff operators on the Lebesgue spaces with power weights. In some cases, these conditions are also necessary and the corresponding operator norms are worked out. We extend and improve some known results in $[6,11]$.

Mathematics subject classification (2010): 26D10, 26D15, 42B35, 46E30.

Keywords and phrases: Hausdorff operators, Hardy operator, Cesàro operator, Young's inequality.

\section{REFERENCES}

[1] K. F. ANDERSEN, Boundedness of Hausdorff operators on $L^{p}\left(\mathrm{R}^{n}\right), H^{1}\left(\mathrm{R}^{n}\right)$, and $B M O\left(\mathrm{R}^{n}\right)$, Acta Sci. Math. (Szeged) 69 (2003), 409-418.

[2] G. BROWn AND F. MóRICZ, The Hausdorff operator and the quasi Hausdorff operators on the space $L^{p}, 1 \leqslant p<\infty$, Math. Inequal. Appl. 3 (2000), 105-115.

[3] G. BRown AND F. MóRICZ, Multivariate Hausdorff operators on the spaces $L^{p}\left(\mathrm{R}^{n}\right)$, J. Math. Anal. Appl. 271 (2002), 443-454.

[4] J. C. Chen, D. S. FAn AND J. LI, Hausdorff operators on function spaces, Chin. Annal. Math. Ser. B 33 (2012), 537-556.

[5] J. C. Chen, D. S. FAn, AND S. L. WANG, Hausdorff operators on Eulidean space, Appl. Math. J. Chinese Univ. Ser. B. 28 (2013), 548-564.

[6] J. C. Chen, D. S. FAN AND C. J. ZHANG, Multilinear Hausdorf operators and their best constants, Acta Math. Sinica (English Ser.) 28 (2012), 1521-1530.

[7] J. C. ChEN, D. S. FAN AND C. J. ZHANG, Boundedness of Hausdorff operators on some product Hardy type spaces, Appl. Math. J. Chinese Univ. Ser. B. 27 (2012), 114-126.

[8] M. Christ and L. Grafakos, Best constants for two nonconvolution inequalities, Proc. Amer. Math. Soc. 123 (1995), 1687-1693.

[9] Z. W. FU, L. GRAFAKos, S. Z. LU AND F. Y. ZHAO, Sharp bounds for m-linear Hardy and Hilbert operators, Houst. J. Math. 38 (2012), 225-244.

[10] G. L. GAO AND H. Y. JiA, Commutators of high dimensional Hausdorff operators, J. Funct. Spaces and Appl., 2012 (2012), 12 pp.

[11] G. L. GaO, X. M. Wu And W. C. Guo, Some results for Hausdorff operators, Math. Inequal. Appl. 18 (2015), 155-168.

[12] G. L. GaO And Y. Zhong, Some inequalities for Hausdorff operators, Math. Inequal. Appl. 17 (2014), 1061-1078.

[13] C. Georgakis, The Hausdorff mean of a Fourier-Stieltjes transform, Proc. Amer. Math. Soc. 116 (1992), 465-471.

[14] L. GrafaKos, Classical Fourier Analysis, 2nd edition, New York: Springer Science, Business Media LLC, 2008.

[15] G. H. HARDY, Note on a theorem of Hilbert, Math. Z. 6 (1920), 314-317.

[16] A. Kufner And L.-E. Persson, Weighted Inequalities of Hardy type, Singapore: World Scientific Publishing Co Pte Ltd, 2003.

[17] Y. Kanjin, The Hausdorff operators on the real Hardy spaces $H^{p}(\mathrm{R})$, Studia Math. 148 (2001), $37-45$.

[18] A. K. LERNER AND E. LIFL YAND, Multidimensional Hausdorff operators on the real Hardy spaces, J. Aust. Math. Soc. 83 (2007), 79-86. 
[19] E. LiflyAnd, Open problems on Hausdorff operators, Complex Analysis and potential Theorey, Proceedings of the Conference, Istanbul, Tukley, Sep. 8-14, 2006.

[20] E. LiflyAnd, Boundedness of multidimensional Hausdorff operators on $H^{1}\left(\mathrm{R}^{n}\right)$, Acta Sci. Math.(Szeged) 74 (2008), 845-851.

[21] E. LiflyAND, Hausdorff Operators on Hardy Spaces, Eurasian Math. J. 4 (2013), 101-141.

[22] E. LiflyAnd AND F. MóRICZ, The Hausdorff operators is bounded on the real Hardy $H^{1}(\mathrm{R})$, Proc. Amer. Math. Soc. 128 (2000), 1391-1396.

[23] E. LiflyAnd AND A. MiYACHI, Boundedness of the Hausdorffoperators in $H^{p}$ spaces, $0<p<1$, Studia Math. 194 (2009), 279-292.

[24] F. MóRICZ, Multivariate Hausdorff operators on the spaces $H^{1}\left(\mathrm{R}^{n}\right)$ and $B M O\left(\mathrm{R}^{n}\right)$, Analysis Math. 31 (2005), 31-41.

[25] X. Y. Lin And L. J. Sun, Some estimates on the Hausdorff operator, Acta Sci. Math. (Szeged) 78 (2012), 669-681.

[26] S. L. WANG, Hausdorff operators, Reports in Zhejiang Normal University, 2013.

[27] X. M. WU AND J. C. CHEN, Best constants for Hausdorff operators on $n$-dimensional product spaces, Sci. China Math. 57 (2014), 569-578. 